\title{
Research on Aging
}

http://roa.sagepub.com

\section{Race, Gender, and SES Disparities in Self-Assessed Health, 1974-2004 \\ Jason L. Cummings and Pamela Braboy Jackson \\ Research on Aging 2008; 30; 137 \\ DOI: $10.1177 / 0164027507311835$}

The online version of this article can be found at: http://roa.sagepub.com/cgi/content/abstract/30/2/137

\section{Published by: \\ (3)SAGE}

http://www.sagepublications.com

Additional services and information for Research on Aging can be found at:

Email Alerts: http://roa.sagepub.com/cgi/alerts

Subscriptions: http://roa.sagepub.com/subscriptions

Reprints: http://www.sagepub.com/journalsReprints.nav

Permissions: http://www.sagepub.com/journalsPermissions.nav

Citations http://roa.sagepub.com/cgi/content/refs/30/2/137 


\title{
Race, Gender, and SES Disparities in Self-Assessed Health, 1974-2004
}

\author{
Jason L. Cummings \\ Pamela Braboy Jackson \\ Indiana University
}

\begin{abstract}
Despite improvements in the status of Blacks and women over the past 30 years, racial and gender disparities in mortality and morbidity persist. Using General Social Survey (GSS) data from 1974 to 2004, the authors explore the extent to which race, gender, and socioeconomic status converge to produce differences in self-assessed health. The intersectionality paradigm is used to guide this work on health disparities. The authors find that the gender gap in self-assessed health has narrowed significantly over this 30-year time period. This decreased gap is especially pronounced because of the marked improvement over time in Black women's reports of their health. However, Black women continue to report the lowest levels of self-assessed health even in 2004. In fact, Black women who hold a college degree report worse health than White men, White women, and Black men with a high school diploma.
\end{abstract}

Keywords: health; disparity; race; gender; intersectionality

$\mathrm{R}$ ace, gender, and socioeconomic status (SES) are social status categories that predict the differential distribution of disease, disability, and death in society (Krieger et al. 1993; Geiger 2006; Williams 2005a). In fact, disparities in health extend over the life course despite advances in medical technology and increased access to medical facilities (Arias and Smith 2003; Jackson 2005; Williams 2005b; Williams and Jackson 2005). If Blacks had experienced the same age-adjusted mortality rates as Whites during the decade spanning 1991 to 2000, for example, nearly 900,000

\footnotetext{
Authors' Note: The first author acknowledges the ASA/NIMH Minority Fellowship Program for financial support. The second author acknowledges the Robert Wood Johnson Foundation for financial support. Both authors thank their colleagues for helpful thoughts and comments on the article. Address all correspondence to either author: J. L. Cummings or P. B. Jackson, Department of Sociology, Indiana University, 1020 E. Kirkwood Ave., Bloomington, IN 47405; phone: 812-855-4127; e-mail: jascummi@indiana.edu or pjackson@ indiana.edu.
} 
deaths among Blacks would have been avoided (Woolf 2004). Similar patterns can be garnered from national data of morbidity for women (Ferraro, Farmer, and Wybraniec 1997; Idler 2003) and a host of health outcomes across SES (House et al. 1994; House and Williams 2000; Isaacs and Schroeder 2004; Lantz et al. 2001).

Prior research has attended to variations in self-assessed health by considering these categories separately, demonstrating the important role played by status characteristics in explaining health differentials (Case and Paxson 2005; Schnittker 2007). Nonetheless, some feminist scholars insist that interactions among status characteristics are a more accurate portrayal of the distribution of health in the United States than simple linear models (Weber 2006). While there is much descriptive evidence for this position (see Pamuk et al. 1998), we have fewer studies involving multivariate analyses; thus, differences within and across sociodemographic groups have not been considered in research on self-assessed health.

The purpose of this study is to extend the body of work on health disparities by exploring changes in self-assessed health at the intersection of race, gender, and social class. We argue that the intersectionality paradigm (Weber 2006) described in much feminist research is a useful framework to guide this type of work on health disparities. Thus, we organize this article in the following way. First, we provide some conceptual clarity to the terms race, gender, SES, and self-assessed health. Then we describe some disparities in various health outcomes. From there we introduce the intersectional paradigm and focus on the way in which this perspective can guide the conceptualization of disadvantage as well as inform research findings. Fourth, we turn our attention to trends in disparities since our use of over-time data allows for a long-term view of health. And last, we describe some of the social forces at work in society from 1974 to 2004 that previous research indicates help explain current patterns in perceived health (see Schnittker 2007).

\section{Conceptual Clarification}

The U.S. racial groupings do not capture race in a biological sense but are socially constructed and reflect certain aspects of ethnicity such as common geographic origins, family patterns, language, values, cultural norms, and traditions (American Association of Physical Anthropology 1996; Williams 1997). Nonetheless, because racial minorities have differential access to power and other valued resources in society (including deference, respect, and access to safe neighborhoods), race has meaning as a 
social category. To acknowledge preferences in the use of racial terms, we take into account the results from a national study of racial identification. According to research by Tucker and colleagues (1996), the majority of Whites prefer to be identified as "White" $(62 \%)$ and the modal label of preference for Blacks is "Black" (44\%). We therefore utilize the terms White and Black throughout this article.

While gender is also a highly visible characteristic, it is the patriarchical power system that defines gender oppression. Gender roles vary across time and societies but throughout recorded history women have commonly occupied a subordinate status. In most Western societies, men continue to claim more power, prestige, and property than women (Healey 1995:25). Nonetheless, changes in the distribution of resources by gender have proven to be much more responsive to antidiscrimination laws compared with race, especially working in the favor of White women (Smith and Welch 1984). These changes may explain why women's self-assessed health has improved over time (Schnittker 2007). There are others, however, who argue that Blacks and women have benefited much from government programs (Carrington, McCue, and Pierce 2000). Perhaps, then, there will be even higher gains in health among Black women compared with other sociodemographic groups. This study will allow us to explore this possibility.

SES is a term conventionally used to refer to an individual's or group's location in the structure of society, which determines differential access to power, privilege, and desirable resources. It is typically assessed by education, income, or occupational status. We explore these relationships using education and income to measure SES since there is growing evidence that these indicators are neither interchangeable nor equivalent across sociodemographic groups (see Williams 2004). In general, Whites relative to Blacks and men relative to women have higher levels of SES (Bauman and Graf 2003; Fronczek and Johnson 2003; Welniak and Posey 2005). It is not surprising to find, then, that Black women are the most disadvantaged, especially in terms of rates of poverty (McKinnon 2003).

Self-assessed health is an individual's perception of his or her general well-being and quality of life rather than an objective evaluation of the absence of disease. It is often referred to as perceived health (Johnson and Wolinsky 1993), assessed health (Ferraro et al. 1997), subjective health (Drevenstedt 1998; Musick 1996), and self-rated health (Frankenberg and Jones 2004; Idler 2003; McDonough and Berglund 2003). This indicator of health is not biased toward inclusion of gender-specific health problems (Ross and Bird 1994) and has been found to be a valid measure across racial and/or ethnic groups (Chandola and Jenkinson 2000). As such, it is a useful 
indicator for analyzing racial and gender disparities in general health and well being over time (Ferraro and Farmer 1996). We use the terms selfassessed health and perceived health interchangeably throughout this study to ease comparisons with prior research.

\section{Disparities in Self-Assessed Health}

There is a strong association between poor self-assessed health and morbidity (Idler 2003), mortality (Idler 1992; Idler and Benyamini 1997; Idler and Stanislav 1991), functional ability (Farmer and Ferraro 1997; Idler 1995; Idler, Russell, and Davis 2000), minor health problems (McDonough and Amick 2001), and physical disability (Rakowski and Cryan 1990; Whitelaw and Liang 1991). In terms of the social distribution of selfassessed health, studies find that Whites report better health than Blacks. More specifically, using a 15-year panel study of adults interviewed between 1971 and 1987, Ferraro and Farmer (1996) found that Blacks have lower perceived health than Whites and perceived health declined at a faster rate for Blacks compared to their White counterparts. Contrary to these findings on race differences in perceived health, gender patterns are somewhat more complicated. Some research finds that women report poorer self-assessed health than men (Idler 2003). More recently, Schnittker (2007) demonstrates an improvement over time in women's self-assessed health to the point where by the year 2004, no significant gender differences were found between men and women in reports of self-assessed health.

Many of these race and gender patterns hold when a wide variety of demographic factors are taken into consideration, including SES. SES is one of the most robust determinants of variations in health where low SES is associated with worse perceived health (House et al. 1994; Williams and Collins 1995). More pointedly, however, is the power of SES in determining perceived health across race and gender. Table 1 presents the percentage of persons in 1995 reporting fair or poor health by income for Black and White men and women in the United States (National Center for Health Statistics [NCHS] 2000). These data reveal that there are large differences in perceived health by income for Blacks and Whites. Moreover, the largest effects of SES are at the lowest categories of income although there is a stepwise progression of risk in the relationship between SES and health status, with each higher level of income associated with better health status for both men and women in each racial group. At the same time, some racial and/or ethnic and gender differences remain evident when groups are 
Table 1

Percentage of Men and Women Reporting Fair or Poor Health by Race and Income, 1995

\begin{tabular}{lrrrrr}
\hline & \multicolumn{3}{c}{ Men } & & \multicolumn{2}{c}{ Women } \\
\cline { 2 - 3 } \cline { 5 - 6 } Household Income & White & Black & & White & Black \\
\hline Poor & 30.5 & 37.4 & & 30.2 & 38.2 \\
Near poor & 21.3 & 22.6 & & 17.9 & 26.1 \\
Middle income & 9.3 & 13.1 & & 9.2 & 14.6 \\
High income & 4.2 & 5.0 & & 5.8 & 9.2 \\
\hline
\end{tabular}

Source: National Center for Health Statistics (2000).

Note: Poor = below federal poverty level; Near poor = less than twice the poverty level; Middle income $=$ more than twice the poverty level but less than $\$ 50,000$; High income $=$ $\$ 50,000$ or more.

compared at similar levels of SES. For example, when race and gender are explored as dual statuses, we find that Black women report poorer health than the other three race-gender group combinations regardless of level of income. However, the highest percentage of those who report fair or poor health are Black and impoverished (NCHS 2000).

Clearly, the associations among race, gender, and SES and health are complex. National data reveal that the patterns appear to vary depending on the specific group and specific indicator of health status under consideration (Pamuk et al. 1998). For example, it is frequently observed, for multiple indicators of health status, that differences between socioeconomic categories within each racial group are larger than differences between races (Navarro 1989; Williams 1999). The health benefits of higher SES stem from several factors. First, individuals who have high incomes and are highly educated tend to smoke and drink less, exercise more and practice healthier eating habits compared to their less privileged counterparts (Mirowsky, Ross, and Reynolds 2000). Second, high SES individuals generally have greater access to adequate health care and are much more likely to seek preventative medical care (Mutchler and Burr 1991; Verbrugge 1989). Third, having high income and education typically protects individuals from financial strain and other stressors that may have negative effects on health (Mirowsky et al. 2000).

Despite the role played by SES in determining health status, numerous paradoxes are evident when race, gender, and SES are simultaneously considered across some health outcomes (see Jackson and Williams 2006). For example, highly educated Black women have a higher infant mortality rate 
than less educated White women; and the homicide rate of Black males in the highest education category exceeds that of White males in the lowest education group (Pamuk et al. 1998). While the focus of this study is selfassessed health, the paradox facing some members of the Black middle class sensitizes us to the complexity of health disparities. We explore this possibility in our analysis by considering the intersection of these statuses.

\section{Theoretical and Empirical Background}

The intersectional paradigm was introduced to the academic community through Black feminist scholarship (see Mullings 1997 for a discussion of this tradition). Intersectionality theory emphasizes the

simultaneous production of race, class and gender inequality, such that in any given situation, the unique contribution of one factor might be difficult to measure. . . This framework-an advance over earlier models that assumed that advantage and disadvantage simply accumulate, for example, to produce double jeopardy_suggests that the content and implications of gender and race as socially constructed categories vary as a function of each other. (Schulz and Mullings 2006:5)

In other words, these scholars believe that social status positions intertwine to create axes of power differentials that cannot be fully expressed in a paradigm that fails to account for broader systems of social inequality (Weber 2006).

At the micro-level, advocates of this position contend that one of the pathways by which systems of inequality (based on race, gender, and SES) can influence health outcomes is through identity formation (Weber and Para-Medina 2003). Given the set of unexpected health findings for the Black middle class, one could theorize that new identities (and therefore new challenges or new sets of stressors) are formed when multiple minority statuses (linked to limited resources and a different set of relationships) converge within a social space. For example, Black professional women must often navigate within the confines of organizations that are structured by both racial and gender divisions. Patterns of dominance and deference also intersect with these master status characteristics (Jackson and Williams 2006). In general, there is growing evidence that the social class position of Blacks does not afford them the degree of social acceptance by others, nor does it translate into the lifestyle one would expect from a higher socioeconomic position (Cose 1993; Massey and Denton 1993; Williams and 
Collins 2004). Such feelings of rejection have been advocated as an important dimension of overall health and well-being (Keyes 1998).

We contend that the intersectionality perspective is worthy of consideration in research on health disparities, especially in light of persistent discrimination in employment (Darity and Mason 1998; Reid 2002). In a study of the way in which inequalities are perpetuated in the workplace, Kennelly (1999) convincingly demonstrates that "Black women stand at a unique disadvantage to all other racial and gender groups" (p. 169) because of the stereotypes they face on the job, particularly as single mothers. The persistent wage gap in median annual earnings is an example of such discrimination. In 1998, Black women earned 62 cents to every dollar earned by White men compared to 74 cents earned by Black men and 72 cents by White women (National Committee on Pay Equity 2001). Thus, intersectionality theory has the potential for helping us understand the health status of certain disadvantaged groups. It draws our attention to the health disadvantages that may be due to past and persistent inequality. The goal of this study is to explore the extent to which there is some combination of disadvantage that helps explain changes in perceived health over time.

\section{Trends in Socioeconomic Disparities}

Changes over time in disparities at the intersection of race, gender, and SES have not been studied for perceived health. A major challenge facing health scholars is the ability to disentangle the social forces that may be producing the patterns we find in the health disparities literature. Our goal here is to describe the extent to which perceptions in health have changed over a period of time in U.S. history where we witnessed widespread social change. For example, during the early 1970s there was a reduction in the Black-White gap in income perhaps due to demands made by the Civil Rights Movement (Economic Report of the President 1998). Instructively, although the gap in life expectancy at birth between Blacks and Whites in 1970 was 7.6 years, this differential was reduced to 6.3 by 1980 and as low as 5.7 by the year 2000 (Arias and Smith 2003).

Notwithstanding, the 1980s represented a tumultuous period in the United States. There were massive budget cuts in health and social service spending by the Reagan administration. During the period between 1980 and 1991, compared to Whites, the health of Black men and women declined (NCHS 1994). In fact, between 1980 and 1990, the Black-White gap in life expectancy had risen slightly from 6.3 years to 7 years (Arias and Smith 2003). 
On the other hand, levels of educational attainment have increased over this 30-year period. For example, in 1970 approximately $55 \%$ of the adult population had earned a high school diploma. This figure rose to $69 \%$ in $1980,78 \%$ in 1990 , and $84 \%$ by the year 2000 . By 2002 , approximately $89 \%$ of Whites and $79 \%$ of Blacks had attained at least a high school diploma (U.S. Department of Commerce 2003). The annual earnings of all full-time workers also improved over this decade. Women employed full time in 1981 earned 59\% of the annual earnings of men but by 1995 this ratio was $71 \%$ (Blau 1998). Since the early 1990s, women's annual earnings relative to men's have increased albeit at a much slower rate (U.S. Census Bureau 2004). In other instances, the wage gap has reverted to earlier rates. The 1975 wage gap for Black men (74.3\%), for example, closely mirrored that of 1998 (74.9\%) and the 1998 wage gap for Black women $(62.6 \%)$ was close to the 1990 report $(62.5 \%)$. Overall, the gender wage ratio in 2004 was the same as that reached in 2002, 76.6\% (National Committee on Pay Equity 2001), and the Black-White gap in income remains. Given such fluctuations, we expect changes in health perceptions. While we cannot take into account the actual impact of macro-level social factors, we consider if current labor market and marital status transitions help explain changes in perceived health over time. We briefly describe these transitions below.

\section{Social Factors}

Periods of unemployment are often problematic for individuals and their families. In terms of health, the employed report lower levels of chronic conditions, fewer acute health conditions, and better self-reported health (Kessler, House, and Turner 1987; Linn, Sandifer and Stein 1985; Pavalko and Smith 1999; Pearlin et al. 1981; Ross and Mirowsky 1995) compared to the unemployed. The unemployment rate in the United States fluctuated during the 30-year span marking the 1970s to the year 2000. For example, in 1970 there were approximately 4 million Americans unemployed compared to 7.6 million in 1980. These figures declined in the 1990s so that 7 million Americans were unemployed in 1990 but only 5.8 million were out of the labor market by 1999 (U.S. Census Bureau 2000).

The last three decades of the 20th century also saw increases in separation and divorce as well as significant declines and/or delays in marriage (Qian and Preston 1993; Rodgers and Thornton 1985). From 1970 to 1998 for instance, the marriage rate declined by $30 \%$ and the rate of divorces and annulments increased by about $20 \%$ (NCHS 1999). Nonetheless, the 
divorce rate has been steadily declining since 1992 from a high of $48 \%$ to $37 \%$ in 2004 (Munson and Sutton 2005).

Research consistently finds a health advantage for the married. Those who are married exhibit higher levels of life satisfaction and happiness (Jackson 1997) while experiencing fewer chronic health conditions (Waite 1995) and longer life spans (Lillard and Panis 1996; Rogers 1995) than the unmarried. In contrast, marital dissolution often results in declines in selfassessed health (Williams and Umberson 2004). We seek to explore the extent to which employment and marital status shape changing perceptions of health. We combine data from the 1974 to 2004 panels of the General Social Survey (GSS), which span the period when many of these changes in work and family were taking place. It is also important to consider labor market and marital transitions since many of the trends described above vary across race, gender, and social class (Willson 2003).

\section{Method}

The data for these analyses come from the GSS collected between 1974 and 2004. ${ }^{1}$ Conducted by the National Opinion Research Center (NORC), the GSS is one of the most widely used and well-respected social science data sources. Based on a full probability design, each sample is representative of noninstitutionalized adults 18 years of age or older in the United States. ${ }^{2}$ On average, the sample size for each year is approximately 1,500 including an oversample of nearly 300 African Americans in 1982 and 1987. The samples for these years have been weighted in the analysis to be nationally representative for race. The core design of the GSS consists of a series of replicating cross-sectional surveys; allowing researchers to monitor social change and stability over time (see Davis and Smith 1996).

The analyses only include Blacks and Whites because the samples of other racial groups were too small to allow substantive conclusions. Analyses were also restricted to those who responded to the self-rated health item. This criterion excludes roughly $3 \%$ of the total sample. ${ }^{3}$ Finally, some cases were not included due to list-wise deletion; fewer than $9 \%$ of all cases were excluded due to missing values on income, and fewer than $1 \%$ due to nonresponse on all other variables. Respondents who refused to report their income were slightly more likely to be Black and to be interviewed in earlier years $(p<.05)$. These restrictions yield a final sample size of 27,650 cases. 


\section{Measures}

Dependent variable. Self-assessed health is measured by asking respondents "Would you say that your own health, in general, is (1) poor, (2) fair, (3) good, or (4) excellent. Self-assessed health is a valid and reliable measure of overall health status (Chandola and Jenkinson 2000; Mossey and Shapiro 1982; Ross and Mirowsky 1995; Ross and Wu 1995) (see note 3).

Independent variables. In the first regression model, race and gender are coded as dummy variables comparing Blacks (coded 1 ) to Whites (coded 0 ) and females (coded 1) to males (coded 0), respectively. In subsequent models, three dummy variables are used to capture the intersectionality of race and gender (Black men, Black women, and White women; coded 1). The omitted category is White men (coded 0 ). This set of variables is roughly equivalent to, and much more intuitive than, controls for race, gender, and the interaction of race and gender.

SES is captured by education and household income. Education is measured with two dummy variables that compare those with less than a high school diploma (as reference group) to those with a high school diploma (coded 1) and college degree and more (coded 1). Household income (measured in thousands) is in constant 2002 dollars. Originally coded in categories, this variable is recoded into midpoints and the top category $(110,000$ and above $)$ is recoded to $165,000 .^{4}$

Employment status is measured as a single dummy comparing the unemployed (coded 0 ) to the employed (coded 1). ${ }^{5}$ Marital status is coded as a series of 4 dummy variables where never-married, separated, widowed and divorced (each receiving a value of 1 ) are compared to the married (coded 0). These transitions are associated with health perceptions (Hughes and Waite 2002).

Control variables. Several demographic controls are included in the model. To adjust for effects that may be due to age differences across race and gender, the variable age is included throughout all models and is measured as a continuous variable. ${ }^{6}$ Region of the country where the respondent resides is captured in three dummy variables (North, Midwest, and West, coded 1) with those who live in the South as the reference category (coded $0){ }^{7}$ We include this measure here because region is a significant predictor of health status (Hayward, Pienta, and McLaughlin 1997; LeClere, Rogers, and Peters 1997).

Given the time-varying nature of the data, we include a series of variables assessing the year of the survey. Survey year is measured continuously with 
years ranging from 0 (representing 1974) to 30 (representing 2004). Analysis was also conducted where the survey year variable is not assumed to be linear: 19 dichotomous variables were created and included in the model predicting changes in self-assessed health by year. We also estimated all models with four-year categories to predict changes in health status across certain time periods. While we do not present these results in the article (to conserve space), we include several figures that demonstrate the relationship between race, gender, and SES paying particular attention to changes in self-assessed health over time. Statistical models that include several interactions may be sensitive to high collinearity, therefore we calculated variance inflation factor (VIF) scores, which measure the extent to which collinearity inflates the variance of a slope estimate (Fox 1991). We found little evidence of multicollinearity. ${ }^{8}$

\section{Statistical Procedure}

We begin with descriptive statistics showing the relationship between race, gender, SES, and self-assessed health in 1974 and 2004. Here the focus is on disparities within and then across groups. The purpose of this exercise is to explore any changes in these perceptions that might inform our understanding of previously documented differences across our sociodemographic groups (NCHS 2000). In other words, we draw attention to any changes in these patterns over time.

Ordinary Least Squares (OLS) regression is then used to examine the association between our sociodemographic variables and changes in selfassessed health. ${ }^{9}$ Sampling weights are used to adjust for oversampling and other sampling procedures. As previously discussed, declines in marriage and increased labor force opportunities are factors that may have implications on the self-reported health status of the general population. ${ }^{10}$ Consequently, we present a separate model to represent the effect of these factors as they affect racial and gender disparities in relative health status. We also include a final model showing the effect of a series of interaction variables between race, gender, and SES in predicting changes in self-assessed health.

\section{Results}

The descriptive statistics for all variables are provided in Table 2. As shown here, most adults report their health quite positively, with Black women reporting the lowest health scores. Regarding SES, White men have 


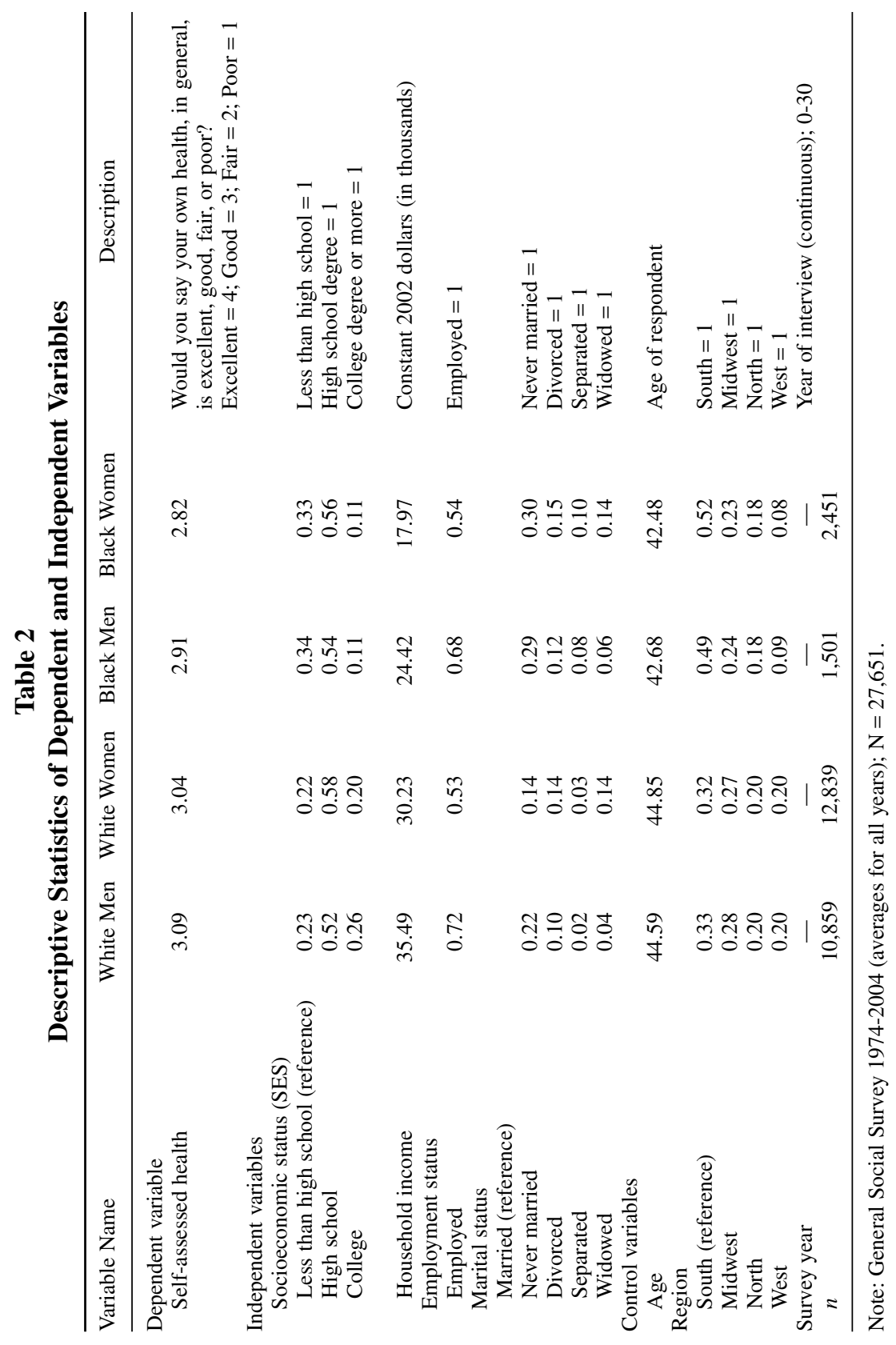


Table 3

Self-Assessed Health by Race, Gender, and Other Social Status Characteristics: General Social Survey 1974-2004

\begin{tabular}{|c|c|c|c|c|c|c|c|c|}
\hline \multirow[b]{2}{*}{ Variable Name } & \multicolumn{2}{|c|}{ White Men } & \multicolumn{2}{|c|}{ White Women } & \multicolumn{2}{|c|}{ Black Men } & \multicolumn{2}{|c|}{ Black Women } \\
\hline & 1974 & 2004 & 1974 & 2004 & 1974 & 2004 & 1974 & 2004 \\
\hline \multicolumn{9}{|l|}{ Education } \\
\hline Less than high school & 2.79 & 2.84 & 2.61 & 2.56 & 2.78 & $2.00^{a}$ & $2.11^{\text {cde }}$ & $2.17^{\mathrm{c}}$ \\
\hline High school & 3.24 & 3.08 & 3.17 & 3.08 & 3.00 & 2.90 & $2.76^{\mathrm{ce}}$ & 3.03 \\
\hline College & 3.34 & 3.34 & 3.23 & 3.34 & $3.25^{\mathrm{a}}$ & 3.33 & $2.83^{\mathrm{a}}$ & 3.29 \\
\hline \multicolumn{9}{|l|}{ Income } \\
\hline Low income & 2.71 & 2.86 & 2.65 & 2.85 & 2.57 & 2.57 & $2.20^{\mathrm{ce}}$ & 2.73 \\
\hline Middle income & 3.14 & 3.07 & 3.11 & 3.06 & 3.05 & 3.05 & $2.65^{\mathrm{ce}}$ & 3.03 \\
\hline High income & 3.35 & 3.27 & 3.25 & 3.33 & 3.36 & 3.05 & 3.09 & 3.35 \\
\hline
\end{tabular}

Note: Less than high school $=0-11$ years of schooling; High school $=12-15$ years of schooling; College $=16$ or more years of schooling. Low income $=$ individuals that fall in the bottom $25 \%$ of the income distribution; Middle income (26\%-50\%); High income (51\%-100\%).

a. $n$ is smaller than 10 .

b. White male versus Black male means significantly different $(p<.05)$.

c. White male versus Black female means significantly different $(p<.05)$.

d. White female versus Black female means significantly different $(p<.05)$.

e. Black male versus Black female means significantly different $(p<.05)$.

the highest percentage of college graduates $(26 \%)$ and the highest mean household income $(\$ 35,000)$. Not very far behind their White male counterpart are White women, $20 \%$ of whom have college degrees. The mean annual household income for White women is $\$ 30,000$. On the contrary, Black men and women are the least likely to have a college degree. And, consistent with national trends, Black women have the lowest household income $(\$ 18,000)$. In terms of employment and marital status, we find that the lowest percentage of those who have been never married are Black (especially women, $30 \%$ ) while the lowest percentage of employed over the 30 -year span are women (53\%-54\%).

Table 3 presents changes in SES for the different race-gender combinations. Again, the purpose of this information is to extend our knowledge of the extent to which SES indicators are associated with changes in selfassessed health across time. We also are able to explore whether trends in reporting health are dependent on the particular measure of SES as suggested by some health scholars (Williams 2004).

As shown here, SES remains a consistent predictor of perceived health. In terms of education, those at the lowest levels report the worst health 
compared to those in higher educational categories. In some cases, there are few differences between those with just a high school diploma and those reporting some college experience (e.g., White men and women in 1974). As expected, the disparities across SES are quite striking. The mean selfassessed health score for Black women in 1974, for example, is significantly lower than the score reported for other groups at the lowest levels of education (compared to White men and women and Black men) and income (compared to White men and Black men). By 2004, however, many of these differences have been reduced to the point where we only find significant differences in self-assessed health between Black women and White men with less than a high school education.

Several notable patterns are evident by 2004. First, Black women are the only group that has more positive ratings of their health in every SES category in 2004 compared to 1974. Second, there is a steeper SES gradient for Blacks in 2004 (with the exception of scores by education for Black men). In other words, Blacks have the greatest within-class disparities in selfassessed health. It would appear that although low SES has always been a hindrance to good health for Black women, it has become a bigger hindrance to perceived good health among Black men.

By 2004, the gender disparities among White and Black adults are highest at the lowest levels of educational attainment, with White men reporting better health. Among Black adults, disparities are largest among high income earners with Black women reporting better perceived health. Overall, the pattern for household income suggests that the gap in health disparities for Whites has remained steady over the span of 30 years while in-group differences have increased for Black men across time but decreased for Black women.

\section{Is Self-Assessed Health Universally Improving or Declining Over Time?}

We begin to address this question by presenting a graph of the observed trends in self-assessed health by race and gender from 1974 to 2004 (see Figure 1). During this period, it appears that White men, and to a lesser extent Black men, have experienced little to no change in their relative health status over time. Women (especially Black women) have reported a higher perception of their health status over time. In general, it appears that Black women have experienced the most dramatic improvements in their self-reported health status. These findings seem to lend support to the idea that racial and gender disparities in health have been quite substantial in the 


\section{Figure 1}

\section{Observed Trends in Self-Rated Health by Race and Gender 1974-2004}

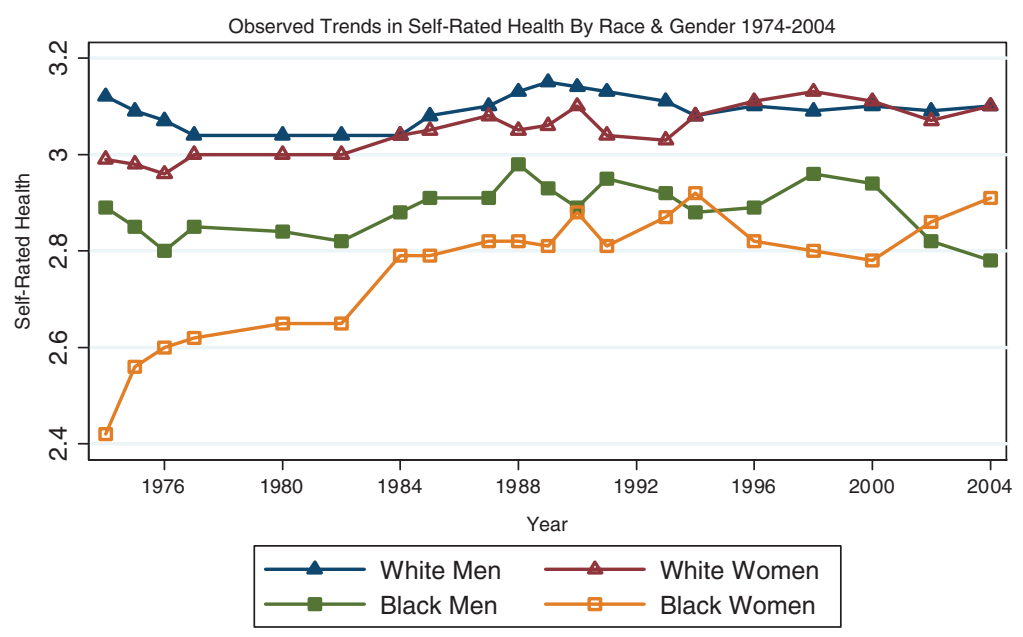

past but more recently the differences in health reporting have become much more similar across groups. These results confirm other reports of an upward trend in women's absolute perceived health (see Schnittker 2007) while simultaneously extending our knowledge of women's self-assessed health across racial groups. A graphic representation of these differences demonstrates that the trend in reports of health varies across race and gender simultaneously with Black women making the largest gains in reports of self-assessed health over the past 30 years.

We also see in Figure 1 that in 1974, White men had a health advantage over all other groups until the mid-1980s when levels of self-assessed health began to converge for White men and women. There are other interesting changes in perceptions of health over time across these four groups. For example, at a time when Black women's perceived health was on the rise (from 1974-1996), Black men's perceptions of their health could best be characterized by a much more stagnant trend. This pattern further emphasizes the importance of examining race and gender at the intersection rather than single categories of adults (race or gender). The period between 1983 and 1987 appeared to be a turning point for Black women when their levels of self-assessed health increased and eventually matched that of Black men. This pattern reoccurs around 1993 when women's perceived health increased while there is a slight decline in Black men's perceptions 
of their health. We witness this reversal again around 2001, where Black women surpass their male peers in levels of self-assessed health. Within this context we witness a decline in Black men's perceived health beginning around 1988-the very time period when other investigators document a steady decline in health among Blacks of all ages (see Ferraro and Farmer 1996). However, the steepest and perhaps most steady declines in the health reporting of Black men occur from 1998 to 2004. By 2004, in fact, Black men were the only group that had lower perceived health scores than in the previous 30-year period (i.e., 1974).

It is also worth noting that it was between 1984 and 1986 when White women were close to achieving parity with White men in self-assessed health. There was a steady decline among White women, however, from 1986 until 1992. A turning point for White women occurred after 1992 where few differences are found between White men and women in perceived health.

In sum, during the 30-year time span from 1974 to 2004, it appears that White men and women have experienced little to no change in their relative perceived health status. Black women have experienced the most dramatic increase in perceptions of health. Also note, however, that a higher percentage of Black women have always reported their health as poor compared to all other groups. What might be most telling about the patterns found for Black women is whether access to more resources help explain these changes in self-assessed health. We now turn attention to the relationship between race, gender, and SES, taking into consideration other widespread social changes, including marital and employment transitions.

\section{How Do Health Disparities Fare Over Time?}

Table 4 includes results from a series of regression models of selfassessed health on the study variables. This table includes a traditional model of health where race and gender are examined independently (Model 1). Here we use multivariate techniques to address the initial question of whether health disparities have persisted over time. The single survey year variable in this model represents the overall trend in self-assessed health over time. If positive, it suggests that on average the general population reporting trend is positive.

We then introduce the race and/or gender group combinations to determine the way in which dual statuses may inform our knowledge of health disparities (Model 2). This approach is consistent with the intersectionality paradigm. We include Race and/or Gender $\times$ Survey Year interactions (Model 3) to demonstrate changes in health reporting over time by race and 
gender. Interaction terms are created by taking each status variable (White women, Black men, and Black women) and multiplying it by the survey year variable. As one would expect from our previous discussion, multiplying these status variables by survey year is nearly identical to, but much more intuitive than, creating three-way Race $\times$ Gender $\times$ Survey Year interaction terms. In these models (that include Race and/or Gender $\times$ Survey interactions), the main effects survey year variable no longer represents the overall health trend in the sample; rather it represents the general pattern for White men. All other Race and/or Gender $\times$ Survey Year interactions reflect whether group-specific trends over time in health reporting significantly differs from the group-specific trends of White men (since they are the reference group). Models 4 and 5 consider the potential role played by SES in altering perceptions of health while Model 6 introduces employment and marital status variables as potential factors contributing to the trend in selfassessed health over time.

Consistent with expectations, Model 1 demonstrates that both Blacks and women rate their health much worse than their White and male counterparts, respectively. Although the patterns demonstrate a "health disadvantage" for women across all survey years, the Black-White health disadvantage is much larger. In fact, while the "penalty" for being female is substantial (about -.04), the price of being Black is more than 6 times that magnitude (-.25).

As we move from Model 1 (baseline model) to Model 2 with the variables that capture the "dual status" of race and gender, note that both the female and Black coefficient in Model 1 overestimated health reporting for Black women and underestimated health reporting for both Black men and White women. When we take into account the multiplicative relationship between race and gender, we find that White women report their health slightly lower than White men (-.03), Black men report their health substantially lower than their White male peers (-.20), and Black women report the worst health $(-.30)$. The multivariate model also indicates that, on average, the sample has reported their health more positively over time.

Again, the next step is to include the Race and/or Gender $\times$ Survey Year interaction terms (Model 3). The coefficients for White and Black women are statistically significant and much larger than the average differences across all samples. ${ }^{11}$ These multivariate results show that while substantial racial and/or gender disparities existed in the perceived health status of minorities and women in the early 1970s (compared to their White male counterparts), ${ }^{12}$ these disparities significantly declined over time (consistent with Figure 1). ${ }^{13}$ 
Table 4

Regression of Self-Assessed Health on Selected Independent Variables: General Social Survey (GSS) 1974-2004 $(N=\mathbf{2 7 , 6 5 0})$

\begin{tabular}{|c|c|c|c|c|c|c|}
\hline & Model 1 & Model 2 & Model 3 & Model 4 & Model 5 & Model 6 \\
\hline Black & $\begin{array}{c}-0.250^{* *} \\
(0.015)\end{array}$ & & & & & \\
\hline Female & $\begin{array}{c}-0.040 * * \\
(0.010)\end{array}$ & & & & & \\
\hline White women & & $\begin{array}{c}-0.032^{* *} \\
(0.010)\end{array}$ & $\begin{array}{c}-0.079 * * \\
(0.020)\end{array}$ & $\begin{array}{c}-0.060 * * \\
(0.020)\end{array}$ & $\begin{array}{c}-0.052 * * \\
(0.020)\end{array}$ & $\begin{array}{c}0.009 \\
(0.020)\end{array}$ \\
\hline Black women & & $\begin{array}{l}-0.309^{* *} \\
(0.019)\end{array}$ & $\begin{array}{c}-0.425 * * \\
(0.039)\end{array}$ & $\begin{array}{c}-0.335 * * \\
(0.039)\end{array}$ & $\begin{array}{c}-0.329 * * \\
(0.039)\end{array}$ & $\begin{array}{l}-0.204 * * \\
(0.039)\end{array}$ \\
\hline Black men & & $\begin{array}{l}-0.208^{* *} \\
(0.023)\end{array}$ & $\begin{array}{c}-0.194 * * \\
(0.045)\end{array}$ & $\begin{array}{c}-0.078 \\
(0.045)\end{array}$ & $\begin{array}{c}-0.135 * * \\
(0.044)\end{array}$ & $\begin{array}{c}-0.030 \\
(0.044)\end{array}$ \\
\hline Survey year & $\begin{array}{l}0.004 * * \\
(0.001)\end{array}$ & $\begin{array}{l}0.004^{* *} \\
(0.001)\end{array}$ & $\begin{array}{c}0.002 \\
(0.001)\end{array}$ & $\begin{array}{l}-0.002 * * \\
(0.001)\end{array}$ & $\begin{array}{c}0.000 \\
(0.001)\end{array}$ & $\begin{array}{c}-0.002^{*} \\
(0.001)\end{array}$ \\
\hline White Women $\times$ Survey Year & & & $\begin{array}{c}0.003 * * \\
(0.001)\end{array}$ & $\begin{array}{l}0.002^{*} \\
(0.001)\end{array}$ & $\begin{array}{l}0.004 * * \\
(0.001)\end{array}$ & $\begin{array}{c}0.002 \\
(0.001)\end{array}$ \\
\hline Black Women $\times$ Survey Year & & & $\begin{array}{l}0.007 * * \\
(0.002)\end{array}$ & $\begin{array}{l}0.007 * * \\
(0.002)\end{array}$ & $\begin{array}{l}0.008^{* *} \\
(0.002)\end{array}$ & $\begin{array}{l}0.006^{* *} \\
(0.002)\end{array}$ \\
\hline Black Men $\times$ Survey Year & & & $\begin{array}{l}-0.001 \\
(0.003)\end{array}$ & $\begin{array}{c}-0.003 \\
(0.003)\end{array}$ & $\begin{array}{c}0.000 \\
(0.002)\end{array}$ & $\begin{array}{c}-0.002 \\
(0.002)\end{array}$ \\
\hline High school & & & & $\begin{array}{l}0.354 * * \\
(0.013)\end{array}$ & & $\begin{array}{l}0.269^{* *} \\
(0.013)\end{array}$ \\
\hline College & & & & $\begin{array}{l}0.605 * * \\
(0.015)\end{array}$ & & $\begin{array}{l}0.433 * * \\
(0.016)\end{array}$ \\
\hline Family income & & & & & $\begin{array}{l}0.006 * * \\
(0.000)\end{array}$ & $\begin{array}{l}0.004 * * \\
(0.000)\end{array}$ \\
\hline Employed & & & & & & $\begin{array}{l}0.210^{* *} \\
(0.011)\end{array}$ \\
\hline Never married & & & & & & $\begin{array}{c}-0.015 \\
(0.013)\end{array}$ \\
\hline Divorced & & & & & & $\begin{array}{l}-0.082^{* * *} \\
(0.015)\end{array}$ \\
\hline Separated & & & & & & $\begin{array}{l}-0.155^{* *} \\
(0.027)\end{array}$ \\
\hline Widowed & & & & & & $\begin{array}{l}-0.011 \\
(0.021)\end{array}$ \\
\hline Constant & $\begin{array}{l}3.644 * * \\
(0.016)\end{array}$ & $\begin{array}{l}3.640 * * \\
(0.016)\end{array}$ & $\begin{array}{l}3.670 * * \\
(0.019)\end{array}$ & $\begin{array}{c}3.267 * * \\
(0.022)\end{array}$ & $\begin{array}{c}3.433 * * \\
(0.020)\end{array}$ & $\begin{array}{l}2.960 * * \\
(0.027)\end{array}$ \\
\hline R-squared & 0.08 & 0.08 & 0.08 & 0.14 & 0.13 & 0.17 \\
\hline
\end{tabular}

Note: All models include controls for age. The final model includes controls for region (not shown). $* p<.05 . * * p<.01$ (two-tailed test; robust standard errors in parentheses). 


\section{The Role of SES}

What role does SES play in improving the health status of racial minorities and women over time? As Model 4 of Table 4 demonstrates, a consideration of educational attainment significantly reduces racial and gender disparities in self-assessed health in 1974. If education was similarly distributed across groups, the health advantage that White men have over Black men would be reduced to insignificance in the initial survey year and all years thereafter (see the "Black Men $\times$ Survey Year" covariate). These results are consistent with the belief that education is a "root component" of social status, which shapes access to a host of resources, such as being employed, job quality, and income (Mirowsky, Ross, and Reynolds 2000). These results also suggest that in some ways education is a much more important and protective health resource for Black men than it may be for other groups. In fact, while household income is also an important predictor of self-assessed health (see Model 5), income only moderately helps explain racial and gender disparities in health.

Model 6 incorporates controls for employment and marital status. The only disparity that remains consistent throughout all models is that Black women report their health much worse than White males in the initial survey year (1974). Although the estimated difference is substantially reduced from Model $3(\beta=-.42)$ to Model $6(\beta=-.20)$, health differentials still remain $(\beta=-.22) .{ }^{14}$

\section{Intersections: Race, Gender, and SES}

Table 5 addresses the question of the utility of the intersectionality paradigm and more specifically whether intersections of race, gender, and SES provide a broader picture of the health patterns previously described. We answer this question by examining several interactions (e.g., Race $\times$ Gender $\times$ Education). Only those models where significant three-way interaction effects were found are presented. We supplement these analyses with a series of figures to demonstrate certain relationships, such as racial and gender differences in the role of education on self-assessed health. These supplementary analyses help us gauge the importance of examining health patterns at the intersection of race, gender, and SES. ${ }^{15}$

As shown in Table 5, racial differences in self-assessed health are more pronounced at the highest levels of education (see Model 1). In the case of Black women for instance, having a college degree has far lower returns to health than for Whites. These patterns are more evident in Figure 2. 
Table 5

Regression of Self-Assessed Health With Selected Interactions: General Social Survey (GSS) 1974-2004 $(N=27,650)$

\begin{tabular}{|c|c|c|}
\hline & \multicolumn{2}{|c|}{ Interaction Models } \\
\hline & Model 1: Education & Model 2: Income \\
\hline White women & $\begin{array}{c}-0.040 \\
(0.028)\end{array}$ & $\begin{array}{c}-0.030 \\
(0.023)\end{array}$ \\
\hline Black women & $\begin{array}{c}-0.202 * * \\
(0.047)\end{array}$ & $\begin{array}{c}-0.243 * * \\
(0.043)\end{array}$ \\
\hline Black men & $\begin{array}{c}-0.047 \\
(0.051)\end{array}$ & $\begin{array}{l}-0.056 \\
(0.050)\end{array}$ \\
\hline High school & $\begin{array}{l}0.233^{* *} \\
(0.021)\end{array}$ & $\begin{array}{l}0.268^{* *} \\
(0.013)\end{array}$ \\
\hline College & $\begin{array}{l}0.408^{* *} \\
(0.023)\end{array}$ & $\begin{array}{l}0.433 * * \\
(0.016)\end{array}$ \\
\hline Family income & $\begin{array}{l}0.004 * * \\
(0.000)\end{array}$ & $\begin{array}{l}0.003 * * \\
(0.000)\end{array}$ \\
\hline White Women $\times$ High School & $\begin{array}{l}0.075^{*} *^{\mathrm{a}} \\
(0.028)\end{array}$ & \\
\hline Black Women $\times$ High School & $\begin{array}{c}0.002 \\
(0.044)\end{array}$ & \\
\hline Black Men $\times$ High School & $\begin{array}{c}0.036 \\
(0.054)\end{array}$ & \\
\hline White Women $\times$ College & $\begin{array}{l}0.071 *^{\mathrm{a}} \\
(0.031)\end{array}$ & \\
\hline Black Women $\times$ College & $\begin{array}{c}-0.114 * \\
(0.059)\end{array}$ & \\
\hline Black Men $\times$ College & $\begin{array}{c}-0.064 \\
(0.072)\end{array}$ & \\
\hline White Women $\times$ Family Income & & $\begin{array}{l}0.001 * * \\
(0.000)\end{array}$ \\
\hline Black Men $\times$ Family Income & & $\begin{array}{c}0.001 \\
(0.001)\end{array}$ \\
\hline Black Women $\times$ Family Income & & $\begin{array}{c}0.002 \\
(0.001)\end{array}$ \\
\hline Constant & $\begin{array}{l}2.983 * * \\
(0.029)\end{array}$ & $\begin{array}{l}2.979 * * \\
(0.028)\end{array}$ \\
\hline R-squared & 0.17 & 0.17 \\
\hline
\end{tabular}

Note: Both models include all controls. Among the coefficients not presented, none of the magnitudes significantly differed from the final model in Table 4 (full table available on request).

a. Significantly different from Black female slope $(p<.05)$.

$* p<.05 . * * p<.01$ (two-tailed test; robust standard errors in parentheses). 


\section{Figure 2}

\section{Racial and Gender Differences in the Role of Education on Self-Rated Health, GSS 1974-2004}

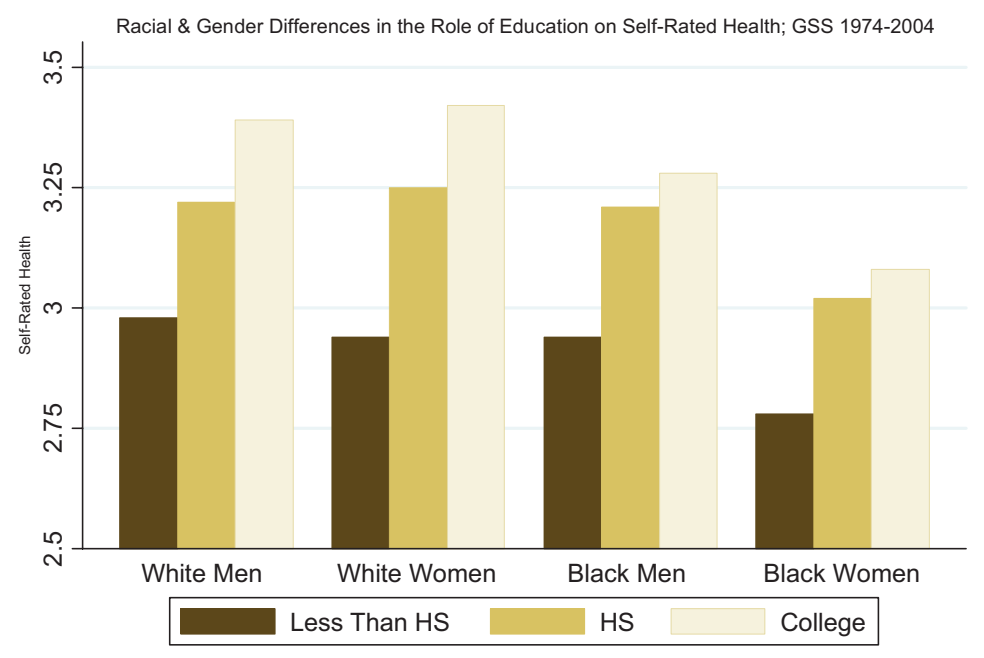

Note: GSS = General Social Survey

As Figure 2 demonstrates, while Whites who have a college degree are substantially healthier than Whites who have a high school diploma, Black female college graduates do not enjoy the same health benefit over their high school counterparts. On the contrary, the health of White women appears to benefit the most from being a high school or college graduate. The most striking pattern, however, is that Black female college graduates report health scores that are substantially lower than the health scores reported by White men, White women, and Black men with a high school diploma. These patterns demonstrate unequal health returns on education for the highest SES group of Black women. Thus, the results of prior research on the health paradox of high infant mortality rates among Black professional women can be extended to include a similar dilemma in terms of self-assessed health.

Not surprisingly, the results regarding income (Table 5, Model 2) also provide some evidence that the relationship between SES and health is more apparent for White women than Black women. Figure 3 shows the multiplicative relationship between race and/or gender, household income, and self-assessed health. 


\section{Figure 3}

\section{Racial and Gender Differences in the Role of Income on Self-Rated Health, GSS 1974-2004}
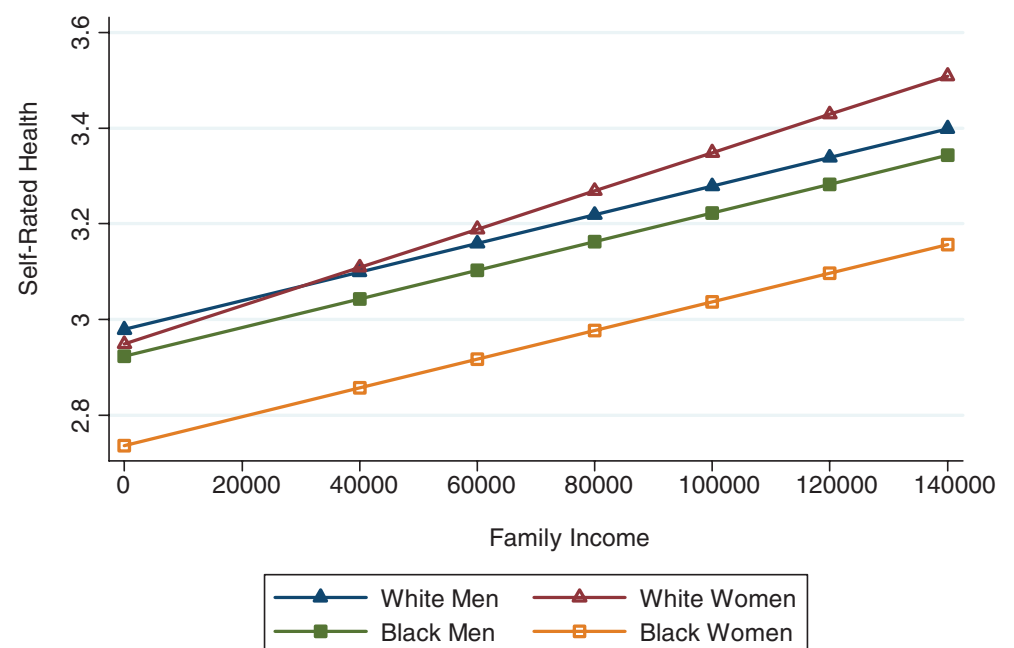

Note: GSS $=$ General Social Survey

Two patterns are noteworthy. First, all groups benefit from increases in income. Second, White women have the greatest slope, experiencing selfassessed health scores at parity with White and Black men at the lowest levels of income. However, at higher levels of household income, White women report the best health while Black women report the lowest ratings of self-assessed health.

\section{Discussion}

Through analyses of nationally representative data for 1974 to 2004, we examined racial and gender disparities in self-assessed health over time. Guided by the intersectionality paradigm, we began by asking if selfassessed health universally improved or declined over time. While a linear approach to the question of racial and gender disparities in health demonstrate that Blacks and women have lower perceptions of health, we conclude that ratings of health have only changed substantially in the United 
States for specific groups of adults. White men have maintained a health advantage over time, competing only with White women whose perceptions have now reached parity with their male peers. Black women have experienced the largest increase in self-assessed health while Black men have experienced many cycles of health assessment that has ultimately resulted in a decline in their perceptions of health (primarily from 19982004). ${ }^{16}$

We then asked what role SES plays in explaining perceived health status. We found that SES accounts for virtually all of the variation in the racial gap in self-assessed health for Black men (relative to White men) across the span of surveys and about half of the variation in women's relative health ratings during the initial survey. While the health advantage that White men have over Black women does not completely wane over time, the gender gap is completely reduced for White women. Finally, if there were no changes in the socioeconomic position of White men over time, we would expect that White men would rate their health significantly worse over time. Based on these findings, we concur with other scholars that improving socioeconomic conditions may play a critical role in closing the racial and gender gap in relative health status (Jackson 2005). Nonetheless, our findings regarding education differ from those presented by Schnittker (2007) in his analysis of this same GSS data. He finds evidence that, compared to men, virtually all the improvement in women's health is attributable to educational attainment. Again, we find that this pattern only holds for White women. Furthermore, we were able to demonstrate differences in the role played by education and income, in particular, in helping explain health disparities between some groups (White women and Black men).

In line with previous work, however, we believe that sharp escalations in women's labor force participation since the early 1970s played a crucial role in reducing the gender gap in relative health status (Schnittker 2007). We find, however, that this pattern only holds for White women, suggesting that the White male to female gap in self-assessed health would not exist if employment opportunities were equal for these groups over time. ${ }^{17}$ Taken together, we were able to demonstrate differences in the role played by SES and role transitions (employment and marital status) in helping explain health disparities between some groups.

We conclude that intersectionality theory serves as a useful framework to launch a discussion about the lives of African Americans, in particular. Unequal power relations between groups and differential access to valuable resources across the life course can result in health disparities over time. Although we were unable to directly assess the structural processes that 
may alter perceptions of health, our findings are consistent with the view that such processes can help eliminate, maintain, and/or exacerbate health status (Hatch 2000). For example, when considering the health of Blacks we found that as education increases, Black men and women actually experience lower returns on their health. Thus even the health of the Black middle class has been stunted over time. And, even though Black women have made the greatest gains in their perceived health, these findings do not contradict the importance of theories of oppression and inequality in explaining health disparities. The initial race to gender gap in self-assessed health was quite substantial in 1974 and has not been eliminated as of 2004. Black women are three times as likely to be uninsured than White women (Meyer and Pavalko 1996), further implying that there will remain stark disparities in their health status compared to other groups in society.

Interestingly, the findings from this study actually highlight the importance of considering ongoing social changes that attempt to address persistent inequalities. For example, legislation that followed the Women's and Civil Rights Movements, no doubt, had a positive impact on women's health in general. Similarly, the Equal Pay Act of 1963 and the Civil Rights Act of 1964 managed to effectively close (although not entirely) the gender gap in pay. A smaller gender gap in wages has been linked to lower female mortality and disability, a relationship that is strongest among White women (Kawachi et al. 1999). Relatedly, it may not be coincidental that "Black progress" in terms of perceptions of health halted during the Reagan and Bush administration; a period which many scholars describe as retrenchment in the social status of African Americans (Omi and Winant 1994).

As such, this study underscores the need for more systematic work examining changes in the stratification system and social policy over time and its subsequent impact on the health and well-being of the general population. We especially advocate for further elaboration of the intersectionality paradigm and encourage more scholars to embrace the complexity of this approach. More work is needed to better understand the ways in which multiple statuses may converge to shape the experiences, opportunities, and life chances of vulnerable populations. To the extent that Black women remain the most disadvantaged in terms of health and experience multiple axes of oppression (Frye 2001), we encourage more research on the processes by which these women navigate the boundaries set by race, gender, and social class categories. In general, we suspect that changes in health perceptions will remain an important marker for health professionals since such perceptions coincide with morbidity and mortality rates (Idler 2003; Idler and Benyamini 1997). 


\section{Notes}

1. With the exception of the following years, GSS has been collected annually: 1979, 1981, 1992, 1995, 1997, and 1999.

2. GSS samples noninstitutionalized adults. Both males and Blacks are at higher risk of institutionalization. While this data cannot address health issues among those incarcerated or account for social selection issues that may be due to the sampling strategy (i.e., some unhealthy men and Blacks may be selected out of the noninstitutionalized population), the data provides a wealth of information on a wide range of topics and is perfectly suited for this study.

3. The self-rated health item was not ascertained in 1978, 1983, or 1986 (11\% of the sample was excluded). As a result of budgetary constraints, the item was only asked of a subset of respondents during 1988 to 1996, 2000, and 2002 (11\% of the restricted sample was excluded). Among respondents who were asked about their health status, fewer than $1 \%$ either "refused" or responded "don't know."

4. GSS does not allow us to account for differences in morbidity, physical disabilities and/or limitations, and chronic health conditions. This poses little concern for us in this study since after accounting for such factors, we would expect the racial and gender gap in selfassessed health to continue to converge or, at the very least, decline.

5. Education was also measured as a continuous variable and several models were estimated with a logarithmic functional form of household income. These alternative measures of SES yielded variance inflation factor scores (in the models with interaction terms) that indicated high levels of multicollinearity. Consequently, the models presented in the article are preferred. We elaborate on other findings regarding multicollinearity in later sections of the article.

6. Individuals who responded that they worked either part-time or full-time were coded as employed. Supplementary analysis (available upon request) shows that in the final models, the effect of being in the labor force on self-reported health status did not vary by work status (full-time/part-time). Consequently, we use this single binary in the analysis.

7. Supplementary analysis indicated that while there is no significant difference between the mean age of Black men and women, Blacks are significantly younger than White men and women. White men are also significantly younger than their White female counterparts. This was ascertained by using a two-sample $t$ test with unequal variances.

8. Each model that included age (and age squared) and all interactive models that included either continuous functional forms of education or household income (logged), produced VIF scores that suggested high levels of multicollinearity. As a result, these variables are not included in the models presented in the article. For the purposes of definition, we adopt the general rule of thumb that a score of 10 typically indicates high multicollinearity.

9. All models were also analyzed using binary logistic models after combining the poor to fair and good to excellent categories and creating a dummy variable. We also explored our findings using ordered logistic models and multinomial logistic models. The general patterns do not change across models but in the few cases where results differ, we discuss these differences in designated footnotes.

10. Health status can be either a cause or a consequence of current marital status, educational attainment or labor force status and cross-sectional analysis provides no basis for identifying the causal direction of the observed association. Thus, social selection and social causation processes may be reflected in the results of this study. Most longitudinal studies indicate that each of these factors (marital status and employment) typically precede health declines (Pavalko, Mossakowski, and Hamilton 2003; Pavalko and Smith 1999). 
11. The survey year coefficient (which is not significant) now represents the health reporting trends for White men across time. The White women and Black women interactions are statistically significant and positive suggesting that women have reported their health much more positively over time with Black women making the largest gains in how they perceive their health during the past 30 years (.007 to .003). In the case of White women, these differences gradually disappear. For Black women and men, these health disparities persist over time.

12. It should be noted that while the change in the health ratings of Black men do not significantly differ from the slope change for either White men or women (model not shown), it does for Black women ( $\mathrm{B}=-.007, t=2.47$ ). In addition, nonlinear variations in this model (i.e., year categories model) demonstrates that for Black men, the decline in their health status from 1998 to 2004 is quite significant and this trend differs from the pattern noted for White men (results available on request).

13. The results from the multinomial logistic base model (including controls for race, gender, time, and age) show that over time all groups were significantly more likely to report their health as "good." The slope increase did not significantly vary across race or gender. Black and White women were more likely to report their health as "excellent" and less likely to report their health as "fair" or "poor" over the span of surveys. Over time, Black and White men were slightly less likely to report their health as "excellent" and Black men were the only group that was more likely to report their health as "poor" over time.

14. These transitions have independent effects on self-assessed health as one might expect. Those who are employed report better self-assessed health. The married report better health than the divorced and separated but not the never-married or widowed. We find in all of the models that aging is related to lower perceived health (Ferraro and Farmer 1996).

15. We included interaction terms that represent the race and/or gender variable with every covariate. No substantial "year interactions" were significant so we do not present any year interactions.

16. An interaction model assessing the impact of employment for the four race and/or gender groups demonstrates that the perceived health of Black men benefit the most from being employed (data available on request). This finding suggests that for Black men, being in the labor force may be an important health resource for combating the absence of a host of SES and/or psychosocial resources such as low education, income, or social support. These patterns also demonstrate that within-group differences among employed and unemployed Black men are quite substantial (more than twice as large as the within-group health disparity for any other group).

17. This discussion of these patterns is supported in a series of decomposition analyses. Changes in education and income have seemed to benefit the health status of Blacks more. Not surprisingly, marital trends have little effect on these changing health trends. The decompositions show movement into the labor force as an important factor for White women in particular. While not discussed here, we also ran some decomposition to examine the role of "cohort replacement" using methods from Firebaugh's (1997) monograph. Cohort replacement factors are at play but labor force status and SES still play a substantial role in accounting for the racial and gender gap in self-assessed health.

\section{References}

American Association of Physical Anthropology. 1996. "AAPA Statement on Biological Aspects of Race.” American Journal of Physical Anthropology 101:569-70. 
Arias, Elizabeth and B. L. Smith. 2003. Deaths: Preliminary Data from 2001. National Vital Statistics Report 51(5):1-44. Hyattsville, MD: National Center for Health Statistics.

Bauman, Kurt and Nikki Graf. 2003. "Educational Attainment: 2000.” United States Census 2000. Washington, DC: U.S. Department of Commerce, Economics and Statistics Administration, U.S. Census Bureau.

Blau, Francine. 1998. "Trends in the Economic Well-Being of Women: 1970-1995.” Journal of Economic Literature 36:112-165.

Carrington, William J., Kristin McCue, and Brooks Pierce. 2000. "Using Establishment Size to Measure the Impact of Title VII and Affirmative Action." The Journal of Human Resources 35:503-23.

Case, Anne and Christina Paxson. 2005. "Sex Differences in Morbidity and Mortality." Demography 42:189-214.

Chandola, Tarani and Crispin Jenkinson. 2000. "Validating Self-Rated Health in Different Ethnic Groups." Ethnicity \& Health 5:151-9.

Cose, Ellis. 1993. The Rage of a Privileged Class. New York: Harper Collins.

Darity, William Jr., and Patrick Mason. 1998. "Evidence on Discrimination in Employment: Codes of Color, Codes of Gender." The Journal of Economic Perspectives 12:63-90.

Davis, James and Tom W. Smith. 1996. General Social Surveys 1972-1996. Chicago: National Opinion Research Center.

Drevenstedt, Greg. 1998. "Race and Ethnic Differences in the Effects of Religious Attendance on Subjective Health." Review of Religious Research 39:245-63.

Economic Report of the President, 1998, With the Annual Report of the Council of Economic Advisers. 1998. Washington, DC: Office of the President.

Farmer, Melissa and Kenneth Ferraro. 1997. "Distress and Perceived Health: Mechanisms of Health Decline." Journal of Health and Social Behavior 39:298-311.

Ferraro, Kenneth and Melissa Farmer. 1996. "Double Jeopardy to Health Hypothesis for African Americans: Analysis and Critique." Journal of Health and Social Behavior 37:27-43.

Ferraro, Kenneth, Melissa Farmer, and John Wybraniec. 1997. "Health Trajectories: LongTerm Dynamics among Black and White Adults." Journal of Health and Social Behavior 38:38-54.

Firebaugh, Glenn. 1997. Analyzing Repeated Surveys. Sage University Paper Series on Quantitative Applications in the Social Sciences, 07-115. Thousand Oaks, CA: Sage.

Fox, John. 1991. Regression Diagnostics. Sage University Paper Series on Quantitative Applications in the Social Sciences, 07-079. Thousand Oaks, CA: Sage.

Frankenberg, Elizabeth and Nathan Jones. 2004. "Self-Rated Health and Mortality: Does the Relationship Extend to a Low-Income Setting?" Journal of Health and Social Behavior 45:441-52.

Fronczek, Peter and Patricia Johnson. 2003. "Occupations: 2000.” United States Census 2000. Washington, DC: U.S. Department of Commerce, Economics and Statistics Administration, U.S. Census Bureau.

Frye, Marilyn. 2001. “Oppression.” Pp. 139-43 in Race, Class, and Gender in the United States: An Integrated Study, edited by P. Rothenberg. New York: Worth.

Geiger, H. Jack. 2006. "Health Disparities: What Do We Know? What Do We Need to Know? What Should We Do?" Pp. 261-88 in Gender, Race, Class, \& Health, edited by A. J. Schulz and L. Mullings. San Francisco: John Wiley.

Hatch, Laurie Russell. 2000. Beyond Gender Differences: Adaptation to Aging in Life Course Perspective. Amityville, NY: Baywood. 
Hayward, Mark D., Amy Pienta, and Diane K. McLaughlin.1997. "Inequality in Men's Mortality: The Socioeconomic Status Gradient and Geographic Context." Journal of Health and Social Behavior 38:313-30.

Healey, J. F. 1995. Race, Ethnicity, Gender, and Class. Thousand Oaks, CA: Pine Forge Press. House, James, James Lepkowski, Ann Kinney, Richard Mero, Ronald Kessler, and A. Regula

Herzog. 1994. "The Social Stratification of Aging and Health." Journal of Health and Social Behavior 35:213-4.

House, James and David Williams. 2000. "Understanding and Reducing Socioeconomic and Racial/Ethnic Disparities in Health." Pp. 81-124 in Promoting Health: Intervention Strategies from Social and Behavioral Research, edited by B. Smedley and S. Leonard Syme. Washington, DC: National Academy Press.

Hughes, Mary Elizabeth and Linda J. Waite. 2002. "Health in Household Context: Living Arrangements and Health in Late Middle Age." Journal of Health and Social Behavior 43:1-21.

Idler, Ellen. 1992. "Self-Assessed Health and Mortality: A Review of Studies." International Review of Health Psychology 1:33-54. . 1995. "Self-Ratings of Health: Do They Also Predict Change in Functional Ability?" Journal of Gerontology: Social Sciences 50B:S344-53.

. 2003. "Gender Differences in Self-Rated Health, in Mortality, and in the Relationship Between the Two." The Gerontologist 43:372-75.

Idler, Ellen and Yael Benyamini. 1997. "Self-Rated Health and Mortality: A Review of Twenty-Seven Community Studies." Journal of Health and Social Behavior 38:21-37.

Idler, Ellen L., Louise Russell, and Diane Davis. 2000. "Self-Rated Health, Survival, and Functional Limitations in the NHEFS." American Journal of Epidemiology 152:874-83.

Idler, Ellen and Kasl Stanislav. 1991. "Health Perceptions and Survival: Do Global Evaluations of Health Status Really Predict Mortality?" Journal of Gerontology: Social Sciences 46:S55-65.

Isaacs, S. L. and S. A. Schroeder. 2004. "Class-The Ignored Determinant of the Nation's Health." New England Journal of Medicine 351:1137-41.

Jackson, Pamela Braboy. 1997. "Role Occupancy and Minority Mental Health." Journal of Health and Social Behavior 38:237-55.

2005. "Health Inequalities among Minority Populations." Journal of Gerontology,

Series $B, 60 \mathrm{~B}$ (Special Issue II):63-7.

Jackson, Pamela Braboy and David R. Williams. 2006. "The Intersection of Race, Gender, and

SES: Health Paradoxes.” Pp. 131-62 in Gender, Race, Class, \& Health: Intersectional Approaches, edited by A. Schulz and L. Mullings. San Francisco: Jossey-Bass.

Johnson, Robert J. and Fredric D. Wolinsky. 1993. "The Structure of Health Status among

Older Adults: Disease, Disability, Functional Limitation, and Perceived Health." Journal of Health and Social Behavior 34:105-21.

Kawachi, Ichiro, Bruce P. Kennedy, Vanita Gupta, and Deborah Prothrow-Stith. 1999.

"Women's Status and Health of Women and Men: A View from the States." Social Science and Medicine 48:21-32.

Kennelly, Ivy. 1999. “'That Single-Mother Element': How White Employers Typify Black Women." Gender \& Society 13:168-92.

Kessler, Ronald, James S. House, and J. Blake Turner. 1987. "Unemployment and Health in a

Community Sample." Journal of Health and Social Behavior 28:51-9.

Keyes, Corey Lee. 1998. "Social Well-Being." Social Psychology Quarterly 61:121-40. 
Krieger, N., D. L. Rowley, A. A. Herman, B. Avery, and M. T. Phillips. 1993. "Racism, Sexism, and Social Class: Implications for Studies of Health, Disease, and Well-Being." American Journal of Preventive Medicine 9:82-122.

Lantz, Paula, John Lynch, James House, James Lepkowski, Richard Mero, Marc Musick, and David Williams. 2001. "Socioeconomic Disparities in Health Change in a Longitudinal Study of U.S. Adults: The Role of Health-Risk Behaviors." Social Science and Medicine 53:29-40.

LeClere, F. B., R. G. Rogers, and K. D. Peters. 1997. "Ethnicity and Mortality in the United States: Individual and Community Correlates." Social Forces 76:169-98.

Lillard, Lee and Constantijn Panis. 1996. "Marital Status and Mortality: The Role of Health (in Mortality).” Demography 33:313-27.

Linn, Margaret, Richard Sandifer, and Shayna Stein. 1985. "Effects of Unemployment on Mental and Physical Health." American Journal of Public Health 75:502-6.

Massey, Douglas and Nancy Denton. 1993. American Apartheid: Segregation and the Making of the Underclass. Cambridge, MA: Harvard University Press.

McDonough, Peggy and Benjamin Amick. 2001. "The Structural Context of Health Selection: A Longitudinal Study of Health and Employment." Social Science and Medicine 53:135-45.

McDonough, Peggy and Pat Berglund. 2003. "Histories of Poverty and Self-Rated Health Trajectories." Journal of Health and Social Behavior 44:198-214.

McKinnon, Jesse. 2003. The Black Population in the United States: March 2002. Washington, DC: U.S. Census Bureau, Current Population Reports, Series P20-541.

Meyer, Madonna Harrington and Eliza Pavalko. 1996. "Family, Work, and Access to Health Insurance Among Mature Women." Journal of Health and Social Behavior 37:311-25.

Mirowsky, John, Catherine Ross, and John Reynolds. 2000. "Links Between Social Status and Health Status.” Pp. 47-67 in Handbook of Medical Sociology, edited by C. Bird, P. Conrad, and A. Freemont. Upper Saddle River, NJ: Prentice Hall.

Mossey, J. M. and E. Shapiro. 1982. "Self-Rated Health: A Predictor of Mortality among the Elderly." American Journal of Public Health 72:800-8.

Mullings, Leith. 1997. On our Own Terms: Race, Class and Gender in the Lives of African American Women. New York: Routledge.

Munson, M. L. and P. D. Sutton. 2005. "Births, Marriages, Divorces, Deaths: Provisional Data for November 2004.” National Vital Statistics Report 53, no. 19. Hyattsville, MD: National Center for Health Statistics.

Musick, Marc. 1996. "Religion and Subjective Health among Black and White Elders." Journal of Health and Social Behavior 37:221-37.

Mutchler, Jan and Jeffrey Burr. 1991. "Racial Differences in Health and Health Care Service Utilization in Later Life: The Effect of Socioeconomic Status." Journal and Health and Social Behavior 32:342-56.

National Center for Health Statistics (NCHS). 1994. "Excess Deaths and Other Mortality Measures for the Black Population: 1979-81 and 1991." Department of Health and Human Services, Publication (PHS), Washington, DC: Public Health Service, U.S. Government Printing Office.

1999. Marriages and Divorces 1970-1998. [No. 117]. Washington, DC: U.S. Department of Health and Human Services, Public Health Service. 
2000. Age-Adjusted Death Rates for Selected Causes of Death, According to Sex, Race, and Hispanic Origin: United States, Selected Years 1950-99 [Table 30]. Washington, DC: U.S. Department of Health and Human Services, Public Health Service.

National Committee on Pay Equity. 2001. "The Wage Gap: Myths and Facts." Pp. 292-304 in, Race, Class, and Gender in the United States, edited by P. Rothenberg. New York: Worth.

Navarro, Vincent. 1989. "Race or Class, or Race and Class." International Journal of Health Services 19:311-14.

Omi, Michael and Howard Winant. 1994. Racial Formation in the United States from the 1960's to the 1990's. New York: Routledge.

Pamuk, E. and others. 1998. Socioeconomic Status and Health Chartbook, Health, United States, 1998. Hyattsville, MD: National Center for Health Statistics.

Pavalko, Eliza, Krysia Mossakowski, and Vanessa Hamilton. 2003. "Does Perceived Discrimination Affect Health? Longitudinal Relationships between Work Discrimination and Women's Physical and Emotional Health." Journal of Health and Social Behavior 43:18-33.

Pavalko, Eliza and Brad Smith. 1999. "The Rhythm of Work: Health Effects of Women's Work Dynamics." Social Forces 77:1141-62.

Pearlin, Leonard, Elizabeth Menaghan, Morton Lieberman, and Joseph Mullan. 1981. "The Stress Process." Journal of Health and Social Behavior 22:337-56.

Qian Zhenchao and Samuel Preston. 1993. "Changes in American Marriage, 1972 to 1987: Availability and Forces of Attraction by Age and Education." American Sociological Review 58:482-95.

Rakowski, William and Cynthia D. Cryan. 1990. "Associations Among Health Perceptions and Health Status Within Three Age Groups.” Journal of Aging and Health 2 (1): 58-80.

Reid, Lori. 2002. "Occupational Segregation, Human Capital, and Motherhood: Black Women's Higher Exit Rates from Full-Time Employment." Gender \& Society 16:728-47.

Rodgers, Willard and Arland Thornton. 1985. "Changing Patterns of First Marriage in the United States (in Research Reports)." Demography 22:265-79.

Rogers. Richard. 1995. "Marriage, Sex and Mortality." Journal of Marriage and Family 57:515-26.

Ross, Catherine and Chloe Bird. 1994. "Sex Stratification and Health Lifestyle: Consequences for Men's and Women's Perceived Health.” Journal of Health and Social Behavior 35:161-78.

Ross, Catherine and John Mirowsky. 1995. "Does Employment Affect Health?" Journal of Health and Social Behavior 36:230-43.

Ross, Catherine E. and Chia-Ling Wu. 1995. "The Links Between Education and Health." American Sociological Review 60:719-45.

Schnittker, Jason. 2007. "Working More and Feeling Better: Women's Health, Employment and Family Life, 1974-2004." American Sociological Review 72:221-38.

Schulz Amy J. and Leith Mullings (eds). 2006. Gender, Race, Class, \& Health: Intersectional Approaches. San Francisco: Jossey-Bass.

Smith, James P. and Finis Welch. 1984. "Affirmative Action and Labor Markets.” Journal of Labor Economics 2:269-301.

Tucker, C., R. McKay, B. Kojetin, R. Harrison, M. de la Puente, L. Stinson, et al. 1996. "Testing Methods of Collecting Racial and Ethnic Information: Results of the Current Population Survey Supplement on Race and Ethnicity." Bureau of Labor Statistical Notes 40:1-149. 
U.S. Census Bureau. 2000. "Employment Status of the Civilian Population: 1950 to 1999." [No. 643]. U.S. Bureau of Labor Statistics, Employment and Earnings. Statistical Abstract of the United States.

2004. "Income, Poverty, and Health Insurance Coverage in the United States: 2004,"

Table A-2. U.S. Census Bureau, Current Population Reports (pp. 60-229). Washington, D.C.: U.S. Government Printing Office.

U.S. Department of Commerce. 2003. Bureau of the Census, U.S. Census of Population, 1960, Volume 1, part 1; Current Population Reports, Series P-20 and previously unpublished tabulations; and 1960 Census Monograph, "Education of the American Population," by John K. Folger and Charles B. Nam. (This table was prepared October 2003.)

Verbrugge, Lois. 1989. "The Twain Meet: Empirical Explanations of Sex Differences in Health and Mortality." Journal of Health and Social Behavior 30:282-304.

Waite, Linda. 1995. "Does Marriage Matter?” Demography 32:483-507.

Weber, Lynn. 2006. "Reconstructing the Landscape of Health Disparities Research: Promoting Dialogue and Collaboration Between Feminist Intersectional and Biomedical Paradigms." Pp. 21-59 in Gender, Race, Class and Health: Intersectioanal Approaches," edited by Amy Schulz and Leith Mullings. San Francisco: Jossey-Bass.

Weber, Lynn and D. Para-Medina. 2003. "Intersectionality and Women's Health: Charting a Path to Eliminating Health Disparities." Advances in Gender Research: Gender Perspectives on Health and Medicine 7:181-230.

Welniak, Ed and Kirby Posey. 2005. "Household Income: 1999.” United States Census 2000.

Washington, DC: U.S. Department of Commerce, Economics and Statistics Administration, U.S. Census Bureau.

Whitelaw, Nancy A. and Jersey Liang. 1991. "The Structure of the OARS Physical Health Measures." Medical Care 29:332-47.

Williams, David R. 1997. "Race and Health: Basic Questions, Emerging Directions." Annual Epidemiology 7:322-33.

. 1999. "Race, SES, and Health: The Added Effects of Racism and Discrimination." Annals of the New York Academy of Sciences 896:173-88. 2004. "Health and the Quality of Life Among Blacks." Pp. 115-38 in The State of

Black America, edited by L. A. Daniels. New York: National Urban League.

2005a. "Patterns and Causes of Disparities in Health." Pp. 115-34 in Policy

Challenges in Modern Health Care, edited by D. Mechanic, L. B. Rogut, D. C. Colby, and

J. R. Knickman. New Brunswick, NJ: Rutgers University Press. 2005b. "The Health of U.S. Racial and Ethnic Populations." Journals of Gerontology

Series B Psychological Sciences and Social Sciences 60:S53-62.

Williams, David R. and Chiquita Collins. 1995. "US Socioeconomic and Racial Differences in Health: Patterns and Explanations." Annual Review of Sociology 21:349-86. 2004. "Reparations: A Viable Strategy to Address the Enigma of Black Health." American Behavioral Scientist 47:977-1000.

Williams, David R. and Pamela Braboy Jackson. 2005. "Social Sources of Racial Disparities in Health." Health Affairs 24:325-34.

Williams, Kristi and Debra Umberson. 2004. "Marital Status, Marital Transitions, and Health: A Gendered Life Course Perspective." Journal of Health and Social Behavior 45:81-98.

Willson, Andrea. 2003. "Race and Women's Income Trajectories: Employment, Marriage, and Income Security over the Life Course." Social Problems 50:87-110.

Woolf, S. 2004. "Society's Choice: The Tradeoff Between Efficacy and Equity and the Lives at Stake." American Journal of Preventive Medicine 49-56. 
Jason L. Cummings is a Ph.D. candidate in the Department of Sociology at Indiana University. His general research and scholarly interests traverse the areas of medical sociology, mental health, culture, race and/or ethnicity, and stratification. Jason's work bridges these areas by exploring the origins, causes, and dynamics of racial and gender disparities in health and well-being. His dissertation examines the link between cultural values, political and/or economic systems, and mental health in the global context. Other projects include racial and/or gender differentials in the effect of employment on health (with Pam Jackson), the connection between incarceration and health (with Tiffani Saunders), and the role of culture in explaining racial differences in health and health care utilization.

Pamela Braboy Jackson is a professor of sociology at Indiana University. Her interests span areas of social psychology, medical sociology, life course sociology, and race and ethnic relations. The major theme underlying her research is the cumulative nature of stress in everyday life-where stress involves a slowly accumulating wear and tear on the body and mind. She embraces a cross-fertilization between stress research and life course sociology. She brings this approach to bear in three broad research areas: (a) social roles, (b) minority group status (including multiple minority statuses), and (c) family well-being. She has published articles on work stress among the Black elite, health inequalities among minorities, and life course processes among adolescents and adults. 